\title{
Pacientes con antecedentes de ACV aumentarían 3 veces el riesgo de fallecer por COVID-19 y retraso en la búsqueda de ayuda
}

\author{
Patients with a history of stroke increase 3 times the risk \\ of death from COVID-19 and delay in seeking help
}

\begin{abstract}
- Ante el distanciamiento social, el aislamiento preventivo y obligatorio y el temor al contagio del COVID-19, los pacientes con ACV no están asistiendo a tiempo para ser tratados. - En nuestro país aproximadamente 100 de cada 100,000 habitantes padecen de un ACV.
\end{abstract}

Desde marzo de 2020 la OMS declaró la pandemia por el virus SARS-CoV-2, produciendo gran impacto en la salud de la población mundial con miles de infectados y muertes. En Perú, los casos por este virus han superado los 200,000 pacientes contagiados y más de 8,000 fallecimientos. Este panorama demuestra que el virus continua en alza y la propagación no se detiene.

Si bien esta pandemia ha significado una amenaza general para toda la población, existen determinadas personas comprendidas como grupos de riesgo, quienes son más vulnerables a desarrollar una enfermedad severa, entre ellas se encuentran los pacientes que padecen de hipertensión arterial, diabetes mellitus, obesidad, enfermedad coronaria, entre otras (1).

Los pacientes con antecedentes de accidentes cerebrovasculares $(\mathrm{ACV})$ presentan con frecuencia los factores de riesgo de suceptibilidad al COVID-19 lo cual aumentarían 3 veces el riesgo de fallecer por COVID-19. El virus puede afectar el sistema nervioso central y periférico. En un estudio en China se reportó que el $36.4 \%$ de los pacientes presentaron manifestaciones neurológicas ${ }^{(2)}$. Los pacientes con COVID-19 presentan alteración en la coagulación e incremento de la respuesta inflamatoria, incrementando el riesgo de formación de coágulos por lo que se hace más probable la ocurrencia de una enfermedad cerebrovascular tanto isquémica como hemorrágica. Incluso se han reportado casos de pacientes con COVID-19 que presentan infarto cerebral sin presentar síntomas respiratorios. Así también se han reportado casos de COVID-19 e ictus en pacientes más jóvenes y de forma más severa $^{(3,4)}$.
Un infarto cerebral o ictus isquémico sucede cuando el flujo de sangre al cerebro se interrumpe por el bloqueo de un coágulo o trombo. Como consecuencia de esta obstrucción, parte del cerebro no recibe flujo y se priva de oxígeno. Por lo tanto, las células cerebrales afectadas no pueden funcionar y mueren en minutos, precisó la Dra. Marla Gallo Guerrero, Neuróloga Clínica y Endovascular. Así también afirma que, ante el distanciamiento social, se ha visto una disminución en más del $50 \%$ de la búsqueda de los pacientes con infarto cerebral para la atención en emergencia. Si bien es indispensable mantener un aislamiento preventivo, se hace necesario saber que el infarto cerebral es una emergencia médica que es tratable y que no puede esperar ya que cada minuto mueren 2 millones de neuronas. Por lo cual es indispensable su reconocimiento precoz y acudir a un centro hospitalario para el tratamiento.

Según el último reporte del Ministerio de Salud (2018), en el Perú, hay una tendencia a un incremento de la mortalidad por ACV. A través de los años esta patología se ha convertido en la segunda causa de muerte. En nuestro país alrededor de 100 de cada 100,000 habitantes padecen de un ACV. La mortalidad hospitalaria a causa de esta enfermedad es aproximadamente del $10 \%$ y en estudios de seguimiento al año se ha encontrado una mortalidad del $20 \%{ }^{(4)}$

Cabe indicar que después de la edad de 55 años, el riesgo de accidente cerebrovascular se duplica, y dos terceras partes de todos los accidentes cerebrovasculares ocurren en personas mayores de 65 años ${ }^{(2)}$.

"Colaboración de Boehringer Ingelheim. 
Ente los principales factores de riesgos que podrían originar posibles fallecimientos y la aparición de secuelas a causa de esta enfermedad, son la falta de reconocimiento de los síntomas; el $90 \%$ de personas no sabe detectar los indicios de un ACV, la demora en llegar al hospital o a una unidad especializada y los retrasos en la toma de decisión del procedimiento a seguir ${ }^{(5)}$.

La especialista Gallo Guerrero, recomienda que ante la aparición de los siguientes síntomas: la alteración para hablar (lenguaje poco entendible o imposibilidad de hablar), falta de fuerza en un lado del cuerpo (brazo y pierna); inicio súbito de dolor de cabeza sin causa aparente y la pérdida del equilibrio para caminar, los pacientes se dirijan, antes de las 4.5 horas, a un centro de salud. Esta es una enfermedad que debe ser tratada de inmediato y por los especialistas. Asimismo, no olvidarse de llevar puesta la mascarilla e implementos de protección necesarios para la prevenir el contagio del COVID-19.

\section{Referencias bibliográficas}

:

1. Mehta P, McAuley DF, Brown M, et al. COVID-19: consider cytokine storm syndromes and immunosuppression. Lancet 2020 Mar 16 pii: S0140-6736(20)30628-0.

2. Mao L, Jin H, Wang M, Hu Y, Chen S, He Q, et al. Neurologic Manifestations of Hospitalized Patients With Coronavirus Disease 2019 in Wuhan, China. JAMA Neurol. Published online April 10, 2020.

3. Cases C. Correspondence Large-Vessel Stroke as a Presenting
Feature of Covid-19 in the Young. 2020;60(1):1-3.

4. Análisis de las causas de mortalidad en el Perú, 1986-2015. Ministerio de Salud. Centro Nacional de Epidemiología, Prevención y Control de Enfermedades. Lima, setiembre, 2018.

5. https://www.geosalud.com/enfermedades\%20cardiovascul ares/accidente-vascular-cerebral/factores-riesgo.html

6. Trejo JM. Ictus como complicación y como factor pronóstico de COVID-19. Neurología. 2020; 35(5):318-322.

Citar como: Pacientes con antecedentes de ACV aumentarian 3 veces el riesgo de fallecer por COVID-19 y retraso en la búsqueda de ayuda. Diagnóstico(Lima). 2021;60(1):61-62.

DOI: 10.33734/diagnostico.v60i1.268

Correspondencia: Carolina Hidalgo Correo electrónico: carolina.hidalgo@boehringer-ingelheim.com 